\title{
Pictures in the service of the Red Cross
}

For quite a long time now the Red Cross has been making use of pictures to publicize its activities and spread its principles.

In the early days, its publications were illustrated by sketches and drawings, and later, by photographs which gradually became-and still are today-an important means for disseminating and communicating the message of the Red Cross.

In addition to static pictures, the Red Cross used moving pictures also, when they came within its means. Films, in the form of reports on various Red Cross activities or as teaching material, have constituted a very significant contribution to the influence and development of the Red Cross among the general public and to the training of Red Cross personnel.

With the purpose of stimulating emulation and production among film producers, the Red Cross has organized competitions for film-makers, both professional and amateur, and festivals where prize-winners receive awards for their work. In the next few pages, International Review reports on the festivals organized by the Red Cross Societies in Hungary, Spain and Bulgaria. ${ }^{1}$

The world stands at present on the threshold of a period in which technical progress is opening the way to considerable innovations in the production, transport, applications and use of pictures in audio-visual techniques. It is therefore appropriate that International Review should print, in the last part of this article, extracts from the address delivered by Mr. F. Stanton, Vice-President of the League of Red Cross Societies, on 30 September 1981 at the inauguration of the International Red Cross Audio-Visual Centre, in Geneva, in which he mentioned the prospects -which appear to be truly astonishing for the non-specialist-now opening

${ }^{1}$ We thank the Red Cross Societies of Hungary, Spain and Bulgaria for the texts which they have sent us and from which we give extracts below. 
for the use of pictures thanks to modern audio-visual techniques and material.

\section{International amateur film festival in Nagykörös}

The Nagykörös Festival was created in 1970 by the Municipal Council of that Hungarian city, firstly to give a new impetus to amateur film production and secondly to arouse public interest in Red Cross activities. The themes proposed to participants were health, protection of the environment and the Red Cross.

From the outset the Hungarian Red Cross supported this festival, which was to be held every two years. From 1972, the League of Red Cross Societies was represented at the festival, which became international in 1980, in view of the number and standard of the films presented.

During the last festival, from 16 to 18 May 1980,18 films by amateur Hungarian producers and 23 by foreign producers were shown; most of them were of a high standard and of excellent technical quality.

A jury of people from different countries awarded several prizes: the first prize of the League of Red Cross Societies went to "Flor Final" by Francisco Fabregat (Spain); the Hungarian Red Cross prize was awarded to the Plovdiv (Bulgaria) amateur film club; the prize of the International Association of Amateur Producers went to another Spaniard, Carlos Tomás Ruiz; and the jury's first prize was won by the Hungarian György Nagy.

There is no doubt that the development of this international festival will prove extremely effective in increasing public awareness of Red Cross objectives.

\section{National amateur film festival in Spain}

With the help of a large film manufacturing company, the Spanish Red Cross organized for the first time, in 1980, a national amateur film festival which met with considerable success.

Among the variety of themes proposed, the Spanish producers showed a distinct preference for the problems of solitude, drugs, elderly people, the deterioration of nature, the physically handicapped, fringe groups and freedom, all of which are profound and difficult subjects to deal with, especially in short films lasting a maximum of fifteen minutes and with the limited technical possibilities offered by Super-8, whether with or without sound. Yet participation in this first festival was high, with 34 films presented, which is extremely encouraging for the Spanish Red Cross. 
A jury composed of persons from artistic circles unanimously awarded the first and second prizes to two films: "Flor Final" by the amateur producer Francisco Fabregat de Castellon de la Plana and "Naturaleza Perdida" by José Carlos Tomas Ruiz; this enabled both producers to take part in the Nagykörös International Festival, where their films also won prizes.

Considering the success of this first festival, the Spanish Red Cross intends to continue encouraging the production of amateur films on Red Cross themes.

\section{Varna film festivals}

The Tenth International Festival of Red Cross and Health Films will take place from 16 to 25 June 1983 in Varna, Bulgaria.

This event will be a milestone in the history of the Varna Festivals, and a time to look back, take stock and consider the future of this international film forum, unique in the world of cinema and television.

The first Festival was organized by the Bulgarian Red Cross in 1965, with the co-operation of the League of Red Cross Societies: 53 short films from 16 countries were submitted. During the intervening years this event has grown into a major film festival, internationally recognized, bringing together representatives of National Red Cross and Red Crescent Societies, film directors, creative artists and personalities from the medical and health fields.

At the Ninth Festival in 1981 there were 481 entries (124 for the film market) from 53 countries and six international organizations.

The Bulgarian Red Cross organizes the Festival in close co-operation with the League and ICRC. The Festival is under the patronage of the League, ICRC, World Health Organization and UNESCO. The increasing participation of countries and organizations has resulted in its official recognition by the International Federation of Film Producers' Associations, thus placing it among the world's major film festivals, the only festival of films of an entirely humanitarian character.

The film and video cassettes - a recent innovation-presented are divided into four categories: Red Cross films, short and medium length documentaries on health and the environment, full length feature films dealing with topical humanitarian and health subjects and television programmes. Recent Festivals at Varna have also laid stress on the UN theme of the year; in 1980 a special competition was organized for films dedicated to the International Year of Disabled Persons. 
In brief, one can say that the films presented are related to the most important issues of Red Cross and health, covering the widest aspects of humanity, social health, ecology and peace, in accordance with the Festival motto "Through humanity to peace and friendship".

The Festival audiences can reach five thousand persons at a single screening. The films are afterwards discussed by representatives of the Red Cross, of the cinema and television and members of the medical and health professions, at "round tables" and conferences. The Festival thus stimulates the exchange of ideas between people belonging to the cinema, the Red Cross, and medical circles and serves its final aim which is the promotion of the Red Cross.

\section{International Red Cross Audio-Visual Centre}

In an earlier issue, International Review briefly mentioned the inauguration of the International Red Cross Audio-Visual Centre. A few more words appear to be called for in order to describe it better.

The International Red Cross Audio-Visual Centre was set up, and is run jointly by the ICRC and the League of Red Cross Societies. It is at the disposal of National Red Cross Societies, information media and the public at large. The technical means at its disposal allow the Centre to meet the needs of its various users, and to produce and distribute a wide variety of audio-visual material on the history and activities of the Red Cross.

The photographic division of the Centre includes a photo-library containing 40000 photographs and 20000 slides, and a laboratory capable of producing programmes of slide-shows and of multi-images.

As regards 16 and $35 \mathrm{~mm}$ films, the Centre will record the cinematographic production of the whole of the Red Cross movement and promote exchanges and co-production. In addition, it is responsible for running the sale and loan service for films produced by the ICRC and the League.

The Centre is also equipped to produce video programmes. These may be news reports on the Red Cross, documentaries on various aspects of its activities, or educational programmes to teach and train Red Cross personnel and to provide suitable material for schools.

It is also envisaged to use video to develop internal communication within the Red Cross movement.

Although the functions of the Centre are important for information and training within the Red Cross, they should also serve to make Red Cross activities known to the general public. To this end, the 
Centre is eager to keep up regular working relations with the professionals in the audio-visual world, in particular with the televised news services, in Geneva and in other countries.

When the International Red Cross Audio-Visual Centre was inaugurated on 30 September, Mr. F. Stanton, Vice-President of the League and Emeritus Chairman of the American National Red Cross, and a former president of the Columbia Broadcasting System, spoke to those present. The International Review is pleased to reprint extracts from his address.

"... While television had its start before World War II, it was not until the period after the war that it began to fulfill the drean that some of us had for it. Nowadays there are few places in the world where antennas-transmitters as well as receivers-do not mark the horizon. It is estimated that the world population of television receivers is close to 500 million. More television sets than telephones, more than automobiles, more than bathtubs, if you will. Moreover, we are today on the threshhold of television's next quantum step. Technology has opened up new and expanded opportunities for the use of the medium in a multitude of applications.

Now we are on the edge of an enormous variety of developments. We have video cassettes, video discs, video recorders that you and I can operate. We have satellites 22,000 miles overhead that can put down audio and video signals all over the globe. We have cables that can carry over 100 television programs simultaneously into the home. We have digital recordings. We have hi-fi large screen television. We have satellites that can beam their signals direct to the home. In short, we are witness to an explosion in technical developments.

These new offerings from the laboratories and manufacturers open up remarkable challenges for Red Cross. In our National Societies, and for our global efforts. The facilities of the Centre we are opening today are all important to the generation ahead for the production, processing and distribution of audio-video materials that will inform and teach.

In these brief remarks this afternoon I want to separate information and education, although, of course, they overlap. In our use of video or audio facilities we can tell our special audiences about what is happening: this meeting here today, the International Conference in 
Manila, or meetings elsewhere in the world which have significance for Red Cross.

Another application for Red Cross could involve actuality reporting by camera of a disaster or emergency. Showing the flooded areas or the aftermath of an earthquake. The pictures and sounds could be based on Red Cross camera work on location, or they could be the work of others on the scene. Or a combination.

But whether it is a Red Cross meeting in Geneva or a natural disaster in some remote area on this planet, this new Centre, its experts and its equipment could be marshalled to inform the Red Cross world about it. Moreover, parts or all of such reporting could be made available to the regular channels of mass news dissemination, thereby serving Red Cross in building its public image or enhancing it.

When it comes to education, this Centre can produce recordings on film, on tape, on discs, that will show selected audiences how to do specific things, from disaster preparedness to the collection and processing of blood. Some of these will be general presentations involving people talking to people, recorded in this studio. Others will be highly technical, involving perhaps animated scientific sequences and a variety of materials from Red Cross research in blood.

Once the product of this facility is available or completed, it can be distributed in several different ways. Here again the expanding techniques open up many avenues for putting our product into the hands of the ultimate user. It is possible today to distribute our work to National Societies by satellite, by leasing time on one or more of the existing services just as we use international telephone voice circuits. Until our needs are more demanding and until our users are equipped and the costs of satellite transmission are within our reach, we can depend on video cassettes or video discs and turn to the postal service for distribution.

From that point on, distribution within a society or a country or a village will depend solely on local facilities. In some areas today and certainly in many areas tomorrow, there are means to circulate or disseminate video material on what is known as "cable". It's an oversimplification, but cable is not unlike a telephone line that connects the television receiver to the sender. Some hotels, for example, distribute movies to their rooms by cable. In some cities cable systems do the same thing for any resident who wishes to subscribe to the service. Today over one-fourth of all homes in the United States are equipped to receive at least a dozen separate cable services simultaneously, including half a dozen conventional over-the-air programs. During 
the next decade - and certainly before the year 2000-the States will become a wired nation, and we will do our banking, much of our shopping, perhaps our voting and certainly our movie-going by cable. That's another story. But it will be the pattern in many developed societies.

The disc or video cassette displayed on the television receiver can be run or played in whole or in part as many times as desired. One of the current disc systems can be indexed so the viewer can retrieve a specific item or sequence. I can see the time when Red Cross will develop a circulating library of standard reference and training materials on tape or disc.

In the future the skills and technology of the Centre-coupled with outside transmission facilities-could be put to the task of setting up conferences by television. With the ever increasing costs of travel in time, in money, in risk, in congestion, in human wear and tear, the day will come when National Societies-as well as regional groups--will confer by cable or satellite in sound and pictures.

This is happening today in industrial, commercial and professional circles. I sat in one such board of directors meeting recently in which individuals on the Pacific rim, New York and Western Europe met and conferred for two hours. Why not Red Cross?

May I observe on this very pleasant occasion that I firmly believe the Centre will come to play an enormous role in the future of the International Red Cross. Our leaders will devote more time to communicating with their colleagues by the means in this studio. And generally the video approach to informing and educating our Red Cross universe will find greater and greater application through our expanding technologies. Why? Because it is more efficient, it is more effective, and in the end, it approximates experience in the real world.

All of this will not happen overnight. But it has been my experience in working with creative electronics engineers that their time frames estimated for a development are more often than not shorter, shorter not longer, than initially anticipated. Be that as it will, Red Cross is on its way with this superb facility. I salute all who have a hand in this exciting undertaking." 